\title{
Substituição do milho pelo triticale na alimentação de tilápias-do-nilo
}

\section{Leonardo Tachibana ${ }^{1}$, Giovani Sampaio Gonçalves ${ }^{2}$, Igo Gomes Guimarães ${ }^{3}$, Dario Rocha Falcon $^{4}$, Margarida Maria de Barros ${ }^{5}$, Luiz Edivaldo Pezzato ${ }^{5}$}

\author{
1 SAA/Agência Paulista de Tecnologia do Agronegócios (APTA) - Pólo Vale do Ribeira. Caixa Postal 122, CEP: 11900-000, Registro, SP, \\ Brasil. \\ 2 SAA/APTA/Instituto de Pesca - Centro Avançado de Pesquisa Tecnológica do Agronegocio do Pescado Continental - Caixa Postal 1052 \\ CEP: 15025-970, São José do Rio Preto, SP, Brasil. \\ 3 Programa de Pós-graduação em Zootecnia pela Unesp/FMVZ, Distrito de Rubião Junior s/n, CEP: 18.618-000, Botucatu, SP, Brasil. \\ 4 UFRPE, Caixa Postal 560, CEP: 52171-900 Recife, PE, Brasil. \\ 5 Unesp/FMVZ, AquaNutri, Distrito de Rubião Junior s/n, CEP: 18.618-000, Botucatu, SP, Brasil.
}

RESUMO - Avaliou-se a substituição do milho pelo triticale em dietas para tilápias-do-nilo. Os peixes foram submetidos ao teste de desempenho em sistema de aquários (50 L) com temperatura controlada e recirculação da água. Alevinos de $1,7 \pm 0,08 \mathrm{~g}$ foram estocados em 30 aquários, em delineamento inteiramente casualizado, com cinco níveis de substituição $(0,0 ; 25,0 ; 50,0 ; 75,0$ e $100,0 \%)$ do milho por triticale e seis repetições. As características zootécnicas avaliadas foram: sobrevivência, ganho de peso, conversão alimentar aparente, consumo alimentar, índice hepato-somático, índice víscerosomático; parâmetros hematológicos: contagem do número de eritrócitos, taxa de hemoglobina, porcentagem de hematócrito, volume corpuscular médio, concentração de hemoglobina corpuscular média. Aos 60 dias de avaliação, houve maior sobrevivência dos peixes que receberam ração com $25 \%$ de substituição em relação àqueles alimentados com a ração sem triticale. Aos 100 dias de avaliação, os peixes alimentados com ração com triticale no nível de 50\% apresentaram a pior conversão alimentar e o maior consumo de alimento. A inclusão do triticale influenciou os parâmetros hematológicos, aumentando o número de eritrócitos e reduzindo o volume corpuscular médio. A substituição de até 100,0\% do milho por triticale na dieta não prejudica o desempenho e o custo da alimentação nem altera as características de carcaça de alevinos de tilápia-do-nilo.

Palavras-chave: nutrição, Oreochromis niloticus, piscicultura, Triticum turgisecale

\section{Replacing corn with triticale in Nile tilapia feeds}

\begin{abstract}
Corn replacement with triticale in Nile tilapia diets was assessed. The fish were submitted to a performance test in a system of aquariums $(50 \mathrm{~L})$ with controlled temperature and water recirculation. Fingerlings weighing from $1.7 \pm 0.08 \mathrm{~g}$ were stocked in 30 aquaria in a randomized complete block with five replacement levels $(0.0,25.0,50.0,70.0$ and $100.0 \%)$ of corn with triticale and six replications. The performance parameters analyzed were: survival, weight gain, apparent feed conversion, feed intake, cost, hepato-somatic index, viscero-somatic index; blood parameters: number of erythrocytes, hemoglobin concentration, hematocrits percentage, mean corpuscular volume, mean corpuscular hemoglobin concentration. The data were submitted to variance analysis and compared by Duncan's test. At 60 days of assessment there was greater survival of fish that received diet with $25.0 \%$ substitution compared to those fed diet without triticale. At 100 days of assessment the fish fed diet with triticale at the level of $50.0 \%$ presented the worst feed conversion rate and highest feed intake. Triticale inclusion influenced the blood parameters, increasing the number of red blood cells and reducing the mean corpuscular volume. Triticale can replace up to $100 \%$ corn in Nile tilapia fingerling diets without affecting the fish performance, feed cost and carcass quality.
\end{abstract}

Key Words: fish culture, nutrition, Oreochromis niloticus, Triticum turgisecale

\section{Introdução}

O triticale (Triticum turgisecale) é resultado da hibridação do trigo com o centeio e tem como vantagens o teor mais elevado de proteína em comparação ao milho e o menor teor de fibra em comparação ao farelo de trigo. Por conter o genoma do trigo e centeio, tem potencial para combinar as características favoráveis das duas espécies. A principal área de plantio encontra-se em locais marginais aos outros cereais de inverno e apresenta rendimento 
elevado, resistência às doenças e tolerância a solos ácidos (Baier, 1995). As maiores áreas de plantio encontram-se em São Paulo, Paraná, Santa Catarina e Rio Grande do Sul (CONAB, 2006) e o período de colheita coincide com o final da entressafra do milho, o que favorece o uso do triticale em dietas para animais em substituição a outros alimentos energéticos. O uso predominante para a alimentação animal é em empresas integradoras de avicultura e suinocultura (Fagundes, 2003).

O triticale fornece carboidrato como fonte de energia, no entanto, sua utilização pode ser restrita à alimentação de animais monogástricos, em decorrência de fatores antinutricionais presentes no grão e do baixo nível de energia. $\mathrm{O}$ triticale faz parte de uma gama de cereais de inverno que possuem polissacarídeos não-amiláceos, inibidores de tripsina e quimotripsina (Butolo, 2002).

Em frangos de corte, é possível substituir 75,0\% do milho pelo triticale sem prejudicar o desempenho produtivo, o que indica que o preço do triticale precisaria ser 63,0; 45,0 e 43,0\% do preço do milho para compensar a substituição de 25,0; 50,0 e 75,0\%, respectivamente (De Brum et al., 2000).

Em tilápias-do-nilo, foi realizado o estudo da digestibilidade do triticale e encontrados valores de 13,75\% de proteína digestível e $3.230 \mathrm{kcal} / \mathrm{kg}$ de energia digestível, enquanto o milho apresenta 7,18\% de proteína digestível e $3.037 \mathrm{kcal} / \mathrm{kg}$ de energia digestível (Boscolo et al., 2002). Em alevinos de piavuçu (Leporinus macrocephalus), a inclusão do triticale em até $25,72 \%$ da dieta não afeta o desempenho dos animais (Nagae et al., 2001). Em salmão-do-atlântico (Salmo salar), a substituição do farelo de trigo pelo triticale na ração não altera a aceitação, a qualidade do pélete e a composição corporal (Hughes, 1990).

Os objetivos neste experimento foram a substituição do milho pelo triticale em dietas para tilápias-do-nilo e avaliação dos parâmetros zootécnicos e hematológicos.

\section{Material e Métodos}

O experimento foi realizado na Universidade Estadual Paulista (UNESP), Faculdade de Medicina Veterinária e Zootecnia, Departamento de Melhoramento e Nutrição, Laboratório de Nutrição de Organismos Aquáticos Aquanutri, unidade integrada ao Centro de Aqüicultura da UNESP.

Utilizaram-se 150 alevinos com 1,70 $\pm 0,08$ g, distribuídos em 30 aquários (50 L) com temperatura controlada e recirculação da água, em delineamento inteiramente casualizado, com cinco níveis de substituição do milho pelo triticale e seis repetições. Cento e cinquenta alevinos foram distribuídos nos aquários e receberam dietas com 0,$0 ; 25,0 ; 50,0 ; 75,0$ e $100,0 \%$ de substituição do milho pelo triticale, correspondendo a $0 ; 7,5 ; 15,0 ; 22,5$ e $30 \%$, respectivamente (Tabela 1$)$. As dietas foram isoenergéticas e isoproteicas, formuladas com base nos teores de nutrientes e energia digestível dos alimentos e utilizando-se as relações aminoácido:proteína determinadas por Gonçalves et al. (2009). A variedade de triticale utilizada foi a BRS 148 (Embrapa) cultivada no Campus da Unesp/ FCA de Botucatu-SP.

As rações foram misturadas, umedecidas (20\%) e extrusadas em equipamento com capacidade para $25 \mathrm{~kg} / \mathrm{hora}$, secas em estufa com ventilação forçada a $55^{\circ} \mathrm{C}$ durante 24 horas e estocadas em temperatura de $-10{ }^{\circ} \mathrm{C}$. Durante o experimento, as rações eram semanalmente pesadas e transferidas para potes de plástico.

Aos 60 dias de experimento, foi realizada a pesagem intermediária dos peixes para acompanhamento do desenvolvimento. Aos 100 dias, os peixes foram pesados novamente, anestesiados em dose elevada de benzocaína para análises hematológicas e posteriormente sacrificados para pesagem. As características zootécnicas analisadas foram: ganho de peso, conversão alimentar aparente, consumo alimentar, índice hepato-somático e índice víscero-somático.

Foram separados três peixes de cada repetição para pesagem das vísceras e do fígado e as análises da gordura visceral (sem fígado) e do fígado. As análises químicobromatológicas das rações e dos peixes foram realizadas segundo os protocolos da AOAC (1984), e as de proteína, pelo método de Kjeldhal (Nx6,25). A energia foi determinada em bomba calorimétrica $\left(\mathrm{PARR}^{\circledR}\right)$.

Após o período experimental, foram utilizados 12 peixes por tratamento para determinação dos parâmetros hematológicos. Os peixes foram anestesiados com benzocaína (1,0 g/15 L) e o sangue coletado com auxílio de seringa $(1,0 \mathrm{~mL})$ banhada com anticoagulante EDTA $(3,0 \%)$, por meio de punção da veia caudal. A contagem do número de eritrócitos foi realizada pelo método do hemocitômetro, em câmara de Neubauer, utilizando-se o azul de toluidina $\left(\right.$ Merck $\left.^{\circledR}\right)$ a $0,01 \%$, diluído em solução fisiológica $(0,9 \%)$, com pipeta de Thoma, na proporção 1:200; a taxa de hemoglobina foi determinada pelo método da cianometahemoglobina, utilizando-se kit comercial para determinação colorimétrica (Analisa Diagnóstica ${ }^{\circledR}$ ); a porcentagem de hematócrito foi obtida pelo método do microhematócrito (Jain, 1986) e a proteína plasmática total, por meio de refratômetro manual. Calcularam-se, ainda, os índices hematimétricos volume corpuscular médio e a concentração de hemoglobina corpuscular média. 
Tabela 1 - Composição das dietas experimentais, com base na matéria natural

\begin{tabular}{|c|c|c|c|c|c|}
\hline \multirow[b]{2}{*}{ Ingrediente } & \multicolumn{5}{|c|}{ Nível de substituição do milho pelo triticale (\%) } \\
\hline & 0 & 25 & 50 & 75 & 100 \\
\hline Triticale & 0 & 7,5 & 15 & 22,9 & 30,3 \\
\hline Glúten de milho & 5,86 & 5,75 & 5,6 & 5 & 5,1 \\
\hline Farinha de peixe & 10 & 10 & 10 & 10 & 10 \\
\hline Milho & 30 & 23,45 & 15,86 & 8,17 & 0 \\
\hline DL-metionina & 0,4 & 0,4 & 0,4 & 0,4 & 0,4 \\
\hline Treonina & 0,15 & 0,15 & 0,15 & 0,15 & 0,15 \\
\hline Óleo de soja & 0 & 0,15 & 0,6 & 1,2 & 1,76 \\
\hline Fosfato bicálcico & 3,8 & 3,7 & 3,5 & 3,4 & 3,3 \\
\hline Vitamina C & 0,08 & 0,08 & 0,08 & 0,08 & 0,08 \\
\hline Suplemento vitamínico/mineral ${ }^{1}$ & 0,25 & 0,25 & 0,25 & 0,25 & 0,25 \\
\hline Energia digestível (kcal/kg) ${ }^{2}$ & 3.042 & 3.012 & 3.006 & 3.009 & 3.009 \\
\hline Extrato etéreo $(\%)^{3}$ & 2,47 & 2,65 & 2,89 & 3,37 & 3,84 \\
\hline Fibra bruta $(\%)^{3}$ & 5,86 & 5,88 & 6,93 & 7,19 & 6,91 \\
\hline Lisina $^{2}$ & 2,25 & 2,25 & 2,25 & 2,25 & 2,25 \\
\hline Metionina $^{2}$ & 0,8 & 0,8 & 0,81 & 0,81 & 0,82 \\
\hline Treonina ${ }^{2}$ & 1,17 & 1,16 & 1,16 & 1,17 & 1,18 \\
\hline Cálcio total $(\%)^{3}$ & 1,5 & 1,52 & 1,47 & 1,45 & 1,45 \\
\hline Fósforo disponível $(\%)^{2}$ & 0,7 & 0,7 & 0,7 & 0,7 & 0,7 \\
\hline Cinza $(\%)^{3}$ & 8,85 & 9,09 & 9 & 8,77 & 8,69 \\
\hline
\end{tabular}

Os cálculos de custo da ração por quilo de peixe produzido compreendem o custo da ração formulada multiplicado pela conversão alimentar. Os valores dos ingredientes foram obtidos nos mercados locais e fabricantes de ração do estado de São Paulo.

As análises físico-químicas da água foram realizadas semanalmente determinando-se os parâmetros $\mathrm{pH}$ (pHmetro digital), amônia (kit labcon), oxigênio (oxímetro digital) e temperatura.

Os dados obtidos foram submetidos à análise de variância e comparados pelo teste de Duncan. Os dados em porcentagem foram previamente transformados pela fórmula $\mathrm{y}=\operatorname{arcoseno} \sqrt{\mathrm{x}}$ (Mendes, 1999) para posterior análise.

\section{Resultados e Discussão}

Os parâmetros físico-químicos analisados foram adequados para criação de peixes em sistema intensivo (Boyd, 1990). A temperatura foi $25,00 \pm 1,30^{\circ} \mathrm{C} ; \mathrm{pH} 7,10 \pm 0,20$; oxigênio dissolvido $5,8 \pm 1,2 \mathrm{mg} / \mathrm{L}$ e a amônia total manteve-se em níveis não-detectáveis.
Os peixes que receberam as rações com substituição do milho pelo triticale não apresentaram diferenças $(\mathrm{P}<0,05)$ no ganho de peso, no consumo e no conversão alimentar aparente durante 60 dias de alimentação (Tabela 2).

Os dados encontrados assemelham-se aos obtidos por Nagae et al. (2001), que não observaram diferenças no ganho de peso, na conversão alimentar aparente, no consumo alimentar aparente quando alimentou piavuçus (Leporinus macrocephalus) com ração contendo diferentes níveis de triticale. Hughes (1990) também não observou diferenças no desempenho do salmão-do-atlântico alimentado com triticale.

No entanto, De Brum et al. (2000), em pesquisa com aves, observaram redução no ganho de peso e no consumo de ração quando substituíram 100,0\% do milho pelo triticale. Portanto, nestas variáveis as aves respondem de forma diferente da tilápia quando este alimento está presente em grandes quantidades.

As diferenças estatísticas $(\mathrm{P}<0,05)$ demonstraram que a taxa de sobrevivência dos peixes alimentados com ração sem triticale durante 60 dias foi menor que a obtida com 
25,0\% de substituição, que não diferiu em relação aos demais níveis de substituição. Os possíveis fatores nutricionais presentes no triticale, como os $\beta$-glucanos, podem ter auxiliado no aumento da capacidade da resposta imune (Vargas-Albores \& Yepiz-Palscencia, 2000; Verlhac et al., 1996) e no aumento da sobrevivência.

A conversão alimentar aparente não diferiu entre os níveis de substituição do milho pelo triticale, o que demonstra que, apesar de o nível de energia digestível do triticale ser menor que o do milho (Boscolo et al., 2002; Sklan et al., 2004), as dietas formuladas com triticale, suplementadas com óleo, possibilitaram bom aproveitamento dos nutrientes, e não prejudicaram a conversão alimentar.

O custo da ração por unidade de ganho de peso dos peixes que receberam a ração com $75,0 \%$ de substituição do milho pelo triticale na dieta foi menor $(\mathrm{P}<0,05)$ que naqueles alimentados com ração sem triticale e com 50,0\% de substituição, pois a conversão alimentar foi levemente menor. Portanto, seria economicamente viável utilizar o triticale nesse nível de inclusão. Esses resultados, no entanto, não estão de acordo com os encontrados por Nagae et al. (2001), que não observaram diferenças $(P<0,05)$ no custo do peixe produzido com a inclusão de triticale na dieta. Portanto, a inclusão do triticale por períodos de até 60 dias não reduz os parâmetros produtivos zootécnicos e ainda diminui o custo de produção.

Os resultados aos 100 dias de experimento (Tabela 2) indicam que não houve diferença no ganho de peso entre os peixes alimentados com dietas contendo triticale, o que confirma informações de Hughes (1990), que também não observou diferenças quando avaliaram a substituição do trigo pelo triticale dietas para salmão-do-atlântico. De Brum et al. (2000) observaram aumento do ganho de peso das aves alimentadas com 14,46 a 43,37\% de triticale na dieta (1 a 21 dias de idade) e queda neste parâmetro após incluir $62,41 \%$ de triticale ( 1 a 35 dias de idade). Neste experimento houve inclusão de até 30,0\% de triticale, pois tilápias exigem níveis proteicos que impossibilitam a inclusão de maior quantidade na mistura e, possivelmente, não houve efeito negativo dos fatores antinutricionais do triticale. É possível que fases de criação da tilápia que permitam a inclusão maior de triticale, como a fase de terminação, possam reduzir o ganho de peso.

O aumento do ganho de peso com a mistura de dois grãos foi discutido por Belal (1999) como possível efeito sinérgico da diferença do tamanho dos grânulos de amido da cevada e do milho, provocando a degradação em tempos diferentes do amido e liberando gradativamente a glicose. A absorção da glicose ainda pode inibir a absorção de aminoácidos por competição dos sítios no sistema digestório (Anderson et al., 1984). O ganho de peso maior, avaliado pelo índice relativo de comparação, dos peixes que receberam ração com $75,0 \%$ de substituição pode ser devido ao sinergismo dos amidos, com predominância do triticale.

O consumo alimentar dos peixes que receberam ração com 50,0\% de substituição aos cem dias foi maior se comparado ao obtido com o nível de $25,0 \%$ e estes não diferiram dos demais níveis de substituição. A possível explicação para o maior consumo de ração pode ser a composição intermediária da mistura de dois alimentos.

A conversão alimentar aos cem dias foi pior nos peixes que receberam ração com 50,0\% de substituição e não

Tabela 2 - Ganho de peso individual, consumo aparente da dieta, conversão alimentar aparente, sobrevivência e custo/kg de ganho de peso individual de tilápias-do-nilo alimentadas com rações contendo triticale durante 60 e 100 dias

\begin{tabular}{|c|c|c|c|c|c|}
\hline Nível de substituição (\%) & $\begin{array}{l}\text { Ganho de peso } \\
\text { individual (g) }\end{array}$ & $\begin{array}{l}\text { Consumo } \\
\text { aparente }(\mathrm{g})\end{array}$ & $\begin{array}{c}\text { Conversão } \\
\text { alimentar aparente }\end{array}$ & $\begin{array}{c}\text { Sobrevivência } \\
\text { (\%) }\end{array}$ & $\begin{array}{c}\text { Custo }^{1} \\
\text { (R\$/ kg de GPI) }\end{array}$ \\
\hline \multicolumn{6}{|c|}{60 dias } \\
\hline 0,0 & $27,52( \pm 4,28)$ & $27,82( \pm 4,12)$ & $1,01( \pm 0,04)$ & $80,00 \mathrm{~b}( \pm 17,89)$ & $0,6087 \mathrm{a}( \pm 0,0248)$ \\
\hline 25 & $26,92( \pm 3,24)$ & $26,52( \pm 2,87)$ & $0,98( \pm 0,05)$ & $100,00 \mathrm{a}( \pm 0,00)$ & $0,5886 \mathrm{ab}( \pm 0,0300)$ \\
\hline 50 & $26,18( \pm 1,98)$ & $26,72( \pm 1,71)$ & $1,02( \pm 0,05)$ & $90,00 \mathrm{ab}( \pm 10,95)$ & $0,6079 a( \pm 0,0152)$ \\
\hline 75 & $29,26( \pm 3,02)$ & $27,53( \pm 3,22)$ & $0,94( \pm 0,05)$ & $86,66 \mathrm{ab}( \pm 16,33)$ & $0,5575 b( \pm 0,0300)$ \\
\hline 100 & $29,27( \pm 5,14)$ & $28,18( \pm 3,14)$ & $0,98( \pm 0,06)$ & $86,66 \mathrm{ab}( \pm 20,66)$ & $0,5795 \mathrm{ab}( \pm 0,0627)$ \\
\hline $\mathrm{CV}$ & 13,28 & 11,37 & 6,29 & 16,98 & 6,16 \\
\hline \multicolumn{6}{|c|}{100 dias } \\
\hline 0,0 & $69,83( \pm 7,35)$ & $72,24 \mathrm{ab}( \pm 6,66)$ & $1,04 \mathrm{~b}( \pm 0,11)$ & $80,00 \mathrm{~b}( \pm 17,89)$ & $0,6252( \pm 0,2665)$ \\
\hline 25 & $64,73( \pm 6,80)$ & $68,82 \mathrm{~b}( \pm 5,79)$ & $1,06 \mathrm{~b}( \pm 0,06)$ & $100,00 \mathrm{a}( \pm 0,00)$ & $0,6362( \pm 0,0380)$ \\
\hline 50 & $68,12( \pm 6,46)$ & $80,46 a( \pm 4,37)$ & $1,19 \mathrm{a}( \pm 0,10)$ & $90,00 \mathrm{ab}( \pm 10,95)$ & $0,7038( \pm 0,0621)$ \\
\hline 75 & $76,56( \pm 9,39)$ & $77,27 \mathrm{ab}( \pm 9,84)$ & $1,01 \mathrm{~b}( \pm 0,03)$ & $86,66 \mathrm{ab}( \pm 16,33)$ & $0,5985( \pm 0,0208)$ \\
\hline 100 & $73,31( \pm 13,79)$ & $76,05 \mathrm{ab}( \pm 10,46)$ & $1,05 \mathrm{~b}( \pm 0,10)$ & $86,66 \mathrm{ab}( \pm 20,66)$ & $0,6229( \pm 0,0623)$ \\
\hline $\mathrm{CV}$ & 13,13 & 10,32 & 8,02 & 10,71 & 20,47 \\
\hline
\end{tabular}

ab Valores médios seguidos de letras distintas diferem $(\mathrm{P}<0,05)$ pelo teste Duncan.

${ }^{1}$ Preço dos ingredientes/kg: farelo de soja - R\$ 0,46; triticale - R\$ 0,27; glúten de milho - R\$ 1,00; farinha de peixe - R\$ 0,95; milho - R\$ 0,30; farelo de trigo - R\$ 0,26; celulose - R\$ 0,15; lisina - R\$ 8,20; metionina - R\$ 6,90; triptofano - R\$ 9,50; treonina - R\$ 10,20; óleo de soja - R\$ 1,15; fosfato bicálcico - R\$ 0,90; calcáreo - R\$ 0,045 
diferiu entre os demais níveis. Possivelmente, o aumento de consumo provocou menor aproveitamento do alimento ingerido, levando à pior conversão alimentar.

Apos 60 dias de experimento, não houve mais mortalidade, demonstrando maior sensibilidade dos peixes até o peso até $30,00 \mathrm{~g}$ em média. A utilização de 7,5\% (25\% de substituição) de triticale na dieta pode ser benéfica aos alevinos de tilápia-do-nilo até atingirem 30,00 g e pode ser utilizada como alimento funcional para redução de mortalidade. Na fase de 30,00 g a 70,00 g, em média, não houve mortalidade, o que está de acordo com resultados encontrados por Nagae et al. (2001).

$\mathrm{O}$ custo da ração/kg de ganho foi menor nos peixes que receberam ração com 75,0\% de substituição. No nível de 100,0\% de substituição, apesar da ração mais barata, a conversão alimentar é pior que a obtida com o nível de 75,0\% de substituição, o que ocasionou maior custo/kg. Nagae et al. (2001) também não observaram diferença estatística no custo da ração/kg de peixe produzido.

A maior sobrevivência nos peixes que receberam ração com $25 \%$ de inclusão de triticale pode ter sido ocasionada pelo aumento das defesas do animal pela quantidade de glucanos presentes no grão. Portanto, apesar de o $\beta$-glucano presente no triticale ser um antinutricional quando em grande quantidade, em pequena dose, pode ser benéfico ao sistema imunológico.

A substituição do milho pelo triticale na dieta de tilápias não influenciou $(\mathrm{P}<0,05)$ no índice hepatosomático, víscero-somático, gonado-somático e no acúmulo de gordura no peixe (Tabela 3), pois as rações experimentais foram formuladas a fim de se manterem os níveis energéticos e lipídicos.

Os valores de proteína plasmática total, hematócrito, hemoglobina, volume corpuscular médio, concentração de hemoglobina corpuscular média e leucócitos não apresentaram diferenças ( $\mathrm{P}>0,05)$ (Tabela 4). As contagens de eritrócitos diferiram entre si e foram menores nos peixes alimentados com a ração sem triticale, o que indica menor número de eritrócitos. Portanto, a possível ação dos componentes presentes no triticale pode interferir na quantidade de eritrócitos presentes no sangue. O número de eritrócitos assemelha-se aos obtidos em outros trabalhos com valores variando de 1,31 a $2,35 \times 10^{6} / \mu \mathrm{L}$ (Tavares-Dias \& Moraes, 2004).

Tabela 3 - Índice hepato-somático, índice víscero-somático, gordura visceral e gordura hepática de tilápias-do-nilo alimentadas com diferentes níveis níveis de substituição do milho pelo triticale na dieta

\begin{tabular}{ccccc}
\hline Nível de substituição (\%) & Índice hepato-somático (\%) & Índice viscero-somático (\%) & Gordura visceral (\%) & Gordura hepática (\%) \\
\hline 0,0 & $1,47( \pm 0,48)$ & $4,26( \pm 1,06)$ & $9,68( \pm 2,94)$ & $24,59( \pm 15,05)$ \\
25 & $1,27( \pm 0,16)$ & $3,51( \pm 0,49)$ & $7,32( \pm 2,48)$ & $20,58( \pm 8,56)$ \\
50 & $1,13( \pm 0,32)$ & $2,97( \pm 0,46)$ & $8,37( \pm 2,90)$ & $22,29( \pm 9,86)$ \\
75 & $0,98( \pm 0,59)$ & $2,86( \pm 1,41)$ & $7,06( \pm 2,54)$ & $23,51( \pm 12,65)$ \\
100 & $1,18( \pm 0,29)$ & $3,58( \pm 0,70)$ & $8,40( \pm 1,43)$ & $30,52( \pm 8,110)$ \\
CV & 32,80 & 26,21 & 30,71 & 45,17 \\
\hline
\end{tabular}

Tabela 4 - Proteína plasmática total, eritrócitos, hematócrito, hemoglobina, volume corpuscular médio, concentração de hemoglobina corpuscular média e leucócitos totais de alevinos de tilápia-do-nilo alimentados com diferentes níveis de substituição do milho pelo triticale na dieta durante 100 dias

\begin{tabular}{|c|c|c|c|c|c|c|c|}
\hline $\begin{array}{l}\text { Nível de } \\
\text { substituição (\%) }\end{array}$ & $\begin{array}{l}\text { Eritrócitos } \\
\left(10^{6} / \mathrm{mL}\right)\end{array}$ & $\begin{array}{l}\text { Hematócrito } \\
\text { (\%) }\end{array}$ & $\begin{array}{l}\text { Hemoglobina } \\
\text { (g/dL) }\end{array}$ & $\begin{array}{l}\text { Volume corpuscular } \\
\text { médio }^{1}(\mathrm{fL})\end{array}$ & $\begin{array}{c}\text { Hemoglobina corpuscular } \\
\text { média }^{2}(\%)\end{array}$ & $\begin{array}{c}\text { Leucócitos } \\
\text { (leuc/mL) }\end{array}$ & $\begin{array}{c}\text { Proteína plasmática } \\
\text { total (\%) }\end{array}$ \\
\hline 0,0 & $1,68 \mathrm{~b}( \pm 0,14)$ & $27,92( \pm 2,80)$ & $5,69( \pm 0,48)$ & $166,04 \mathrm{a}( \pm 12,54)$ & $20,45( \pm 1,11)$ & $148.583,33( \pm 3.3077,81)$ & $4,88( \pm 0,21)$ \\
\hline 25 & $1,98 \mathrm{a}( \pm 0,19)$ & $27,41( \pm 1,80)$ & $5,98( \pm 0,49)$ & $139,37 \mathrm{~b}( \pm 17,30)$ & $85( \pm 1,63)$ & $121.250,00( \pm 3.9648,14)$ & $4,58( \pm 0,36)$ \\
\hline 75 & $1,95 \mathrm{a}( \pm 0,17)$ & $26,92( \pm 2,50)$ & $5,56( \pm 0,76)$ & $139,45 \mathrm{~b}( \pm 22,25)$ & $20,61( \pm 1,23)$ & $122.416,67( \pm 19.868,11)$ & $4,62( \pm 0,31)$ \\
\hline 100 & $1,87 \mathrm{ab}( \pm 0,13)$ & $29,33( \pm 2,66)$ & $6,31( \pm 0,81)$ & 157,03 a b $( \pm 13,38)$ & $21,47( \pm 1,75)$ & $115.416,67( \pm 28.585,69)$ & $4,69( \pm 0,25)$ \\
\hline
\end{tabular}

ab Valores médios seguidos de letras diferentes, diferem $(\mathrm{P}<0,05)$ pelo teste Duncan.

Valores médios acompanhados de letras iguais, ou sem letra, não diferem entre si.

${ }^{1} \mathrm{VCM}=[(\mathrm{Htc} /$ Erit $) * 10] ;{ }^{2} \mathrm{CHCM}=[(\mathrm{Hb} / \mathrm{Htc}) * 100]$.

O volume corpuscular médio também foi afetado pela inclusão do triticale na dieta. A análise estatística comprovou diferença entre os peixes que receberam ração com diferentes níveis de substituição do milho pelo triticale e que os peixes que receberam ração com nível de $0,0 \%$ de substituição apresentaram o maior volume corpuscular médio, mas não diferiram daqueles que receberam os níveis de 50,0 e 100,0\%, portanto, os valores mantiveram-se dentro dos valores (118,60 a 246,40\%) citados por TavaresDias e Moraes (2004). 


\section{Conclusões}

O triticale pode substituir até $100,0 \%$ do milho em dietas para alevinos de tilápia-do-nilo sem causar prejuízos nas variáveis zootécnicas e no custo da alimentação. A substituição do milho pelo triticale na dieta não altera as características de carcaça.

\section{Agradecimentos}

Ao Cnpq pela bolsa de doutorado e aos estagiários Maria Júlia Santa Rosa, Diego Strich e Adriana de Menezes. Aos colegas William Vicente Narváez Solarte, Geisa Karine Kleeman, Marcelo Vinícius do Carmo e Sá, Hamilton Hisano, Altevir Signor, André Moreira Bordinhon.

\section{Referências}

ANDERSON, J.A.; JACKSON, A.J.; MATTY, A.J. et al. Effect of dietary carbohydrate and fiber on the tilapia Oreochromis niloticus. Aquaculture Research, v.37, p.303-314, 1984.

ASSOCIATION OF OFFICIAL ANALYTICAL CHEMISTS AOAC. Official methods of analysis. 12.ed. Washington, D.C.: $1984.1015 p$.

BAIER, A.C. Potencialidades do triticale no Brasil. In: REUNIÃO BRASILEIRA DE TRITICALE, 4., 1992. Chapecó. Anais... Chapecó: EPAGRI, 1995. 159p.

BELAL, J.E.H. Replacing dietary corn with barley seeds in Nile tilapia, Oreochromis niloticus (L.), feed. Aquaculture Research, v.30, p.265-269, 1999.

BOSCOLO, W.R.; HAYASHI, C.; MEURER, F. Digestibilidade Aparente da Energia e Nutrientes de Alimentos Convencionais e Alternativos para a Tilápia do Nilo (Oreochromis niloticus, L.). Revista Brasileira Zootecnia, v.31, n.2, p.539-545, 2002.

BOYD, C.E. Water quality in ponds for aquaculture. Auburn, Alabama: Alabama Agricultural Experiment Station; Auburn University, 1990. 482p.

BUTOLO, J.E. Qualidade de ingredientes na alimentação animal. Campinas: Colégio Brasileiro de Nutrição Animal, 2002. 430p.

COMPANHIA NACIONAL DE ABASTECIMENTO - CONAB. Safra 2005/2006. Disponível em: <www.conab.gov.br/dowload/ safra/boletim_safra.pdf>. Acesso em: 20/8/2006.
DE BRUM, P.A.R.; ZANOTTO, D.L.; GUIDONI, A.L. et al. Triticale em dietas para frangos de corte. Pesquisa Agropecuária Brasileira, v.35, n.2, p.229-239, 2000.

EMPRESA BRASILEIRA DE PESQUISA AGROPECUÁRIA EMBRAPA. Cultivar de triticale BRS 148. Disponível em: <http://www.cnpt.embrapa.br/culturas/triticale/cultivares/>c_tt148.htm>. Acesso em: 22/8/2006.

FAGUNDES, M.H. 2003. Sementes de triticale. Disponível em: $<$ www.conab.gov.br/download/cas/especiais/TRITICALESEMENTE.pdf $>$. Acesso em: 15/2/2005.

FURUYA, W.M.; BOTARO, D.; NEVES, P.R. et al. Exigência de lisina pela Tilápia do Nilo (Oreochromis niloticus), na fase de terminação. Ciência Rural, v.34, n.5, 2004a.

FURUYA, W.M.; SILVA, L.C.R.; NEVES, P.R. et al. Exigência de metionina + cistina para alevinos de Tilápia do Nilo (Oreochromis niloticus). Ciência Rural, v.34, n.6, 2004b.

GONÇALVES, G.S.; PEZZATO, L.E.; BARROS, M.M. et al. Relação lisina digestível:proteína digestível em rações para tilápias-donilo. Revista Brasileira de Zootecnia, v.38, n.12, p.2299-2305, 2009.

HUGHES, S.G. Use of triticale as a replacement for wheat middlings in diets for Atlantic salmon. Aquaculture, v.90, n.2, p.173-178, 1990.

JAIN, N.C. Schalm's veterinary hematology. 4.ed. Philadelphia: Lea \& Febiger, 1986. 1221p.

MENDES, P.P. Estatística aplicada à aqüicultura. Recife: Bagaço, 1999. 265p.

NAGAE, M.Y.; HAYASHI, C.; GALDIOLI, E.M. Inclusão do triticale em rações para alevinos de piavuçu, Leporinus macrocephalus (Garavello \& Britski, 1988). Acta Scientiarum, v.23, n.4, p.849-853, 2001.

NATIONAL RESEARCH COUNCIL - NRC. Nutrient requirements of fish. Washington, D.C.: National Academy Press, 1993. 115p.

PEZZATO, L.; MIRANDA, E.C.; BARROS, M.M. et al. Digestibilidade aparente de ingredientes pela tilápia-do-nilo (Oreochromis niloticus). Revista Brasileira de Zootecnia, v.31, n.4, p.1595-1604, 2002.

SKLAN, D.; PRAG, T.; LUPATSCH, I. Apparent digestibility coefficients of feed ingredients and their prediction in diets for tilapia Oreochromis niloticus x Oreochromis aureus (Teleostei, Cichlidae). Aquaculture Research, v.35, p.358-364, 2004.

TAVARES-DIAS, M.; RUAS, F.R. Hematologia de peixes teleoteos. Ribeirão Preto: M. Tavares-Dias, 2004. 144p.

VERLHAC, V.; GABAUDANA, J.; OBACHC, A. et al. Influence of dietary glucan and vitamin $C$ on non-specific and specific immune responses of rainbow trout (Oncorhynchus mykiss) Aquaculture, v.143, n.2, p.123-133, 1996.

VARGAS-ALBORES, F.; YEPIZ-PLASCENCIA, G. Beta glucan binding protein and its role in shrimp immune response. Aquaculture, v.191, p.13-21, 2000. 